\title{
The COVID-19 Study of Healthcare and Support Personnel (CHAMPS): Protocol for a Longitudinal Observational Study
}

Peter G Kaufmann ${ }^{1 *}$, PhD; Donna S Havens ${ }^{1^{*}}$, PhD; Janell L Mensinger ${ }^{1^{*}}, \mathrm{PhD}_{\text {; }}$ Patricia K Bradley ${ }^{1^{*}}, \mathrm{PhD}$; Heather $\mathrm{M} \mathrm{Brom}^{1^{*}}, \mathrm{PhD}$; Linda C Copel ${ }^{1 *}, \mathrm{PhD}$; Alexander Costello ${ }^{2^{*}}, \mathrm{MS}$; Christine D'Annunzio ${ }^{{ }^{*}}, \mathrm{MSN}$; Jennifer Dean Durning $^{1 *}$, MSN; Linda Maldonado ${ }^{1 *}, \mathrm{PhD}$; Ann Barrow McKenzie ${ }^{1 *}$, MSN; Suzanne C Smeltzer ${ }^{1 *}$, EdD; Jennifer Yost $^{1 *}, \mathrm{PhD}$; CHAMPS Study Investigators ${ }^{3}$

\footnotetext{
${ }^{1}$ M. Louise Fitzapatrick College of Nursing, Villanova University, Villanova, PA, United States

${ }^{2}$ Department of Mathematics and Statistics, Villanova University, Villanova, PA, United States

${ }^{3}$ Villanova University, Villanova, PA, United States

*these authors contributed equally
}

\section{Corresponding Author:}

Peter G Kaufmann, PhD

M. Louise Fitzapatrick College of Nursing

Villanova University

800 Lancaster Ave

Villanova, PA, 19085

United States

Phone: 16105195972

Email: peter.kaufmann@villanova.edu

\begin{abstract}
Background: Early in the development of the COVID-19 pandemic, it was evident that health care workers, first responders, and other essential workers would face significant stress and workplace demands related to equipment shortages and rapidly growing infections in the general population. Although the effects of other sources of stress on health have been documented, the effects of these unique conditions of the COVID-19 pandemic on the long-term health and well-being of the health care workforce are not known.
\end{abstract}

Objective: The COVID-19 Study of Healthcare and Support Personnel (CHAMPS) was designed to document early and longitudinal effects of the pandemic on the mental and physical health of essential workers engaged in health care. We will investigate mediators and moderators of these effects and evaluate the influence of exposure to stress, including morbidity and mortality, over time. We will also examine the effect of protective factors and resilience on health outcomes.

Methods: The study cohort is a convenience sample recruited nationally through communities, professional organizations, networks, social media, and snowball sampling. Recruitment took place for 13 months to obtain an estimated sample of 2762 adults who provided self-reported information administered on the web through structured questionnaires about their work environment, mental and physical health, and psychosocial factors. Follow-up questionnaires will be administered after 6 months and annually thereafter to ascertain changes in health, well-being, and lifestyle. Participants who consented to be recontacted form the longitudinal cohort and the CHAMPS Registry may be contacted to ascertain their interest in ancillary studies for which they may be eligible.

Results: The study was approved by the Institutional Review Board and launched in May 2020, with grants from Travere Therapeutics Inc, McKesson Corporation, anonymous donors, and internal funding from the M. Louise Fitzpatrick College of Nursing at Villanova University. Recruitment ended in June 2021 after enrolling 2762 participants, 1534 of whom agreed to participate in the longitudinal study and the registry as well as to be contacted about eligibility for future studies.

Conclusions: The CHAMPS Study and Registry will enable the acquisition of detailed data on the effects of extended psychosocial and workplace stress on morbidity and mortality and serve as a platform for ancillary studies related to the COVID-19 pandemic.

Trial Registration: ClinicalTrials.gov NCT04370821; https://clinicaltrials.gov/ct2/show/NCT04370821

International Registered Report Identifier (IRRID)： DERR1-10.2196/30757 
(JMIR Res Protoc 2021;10(10):e30757) doi: 10.2196/30757

\section{KEYWORDS}

COVID-19; SARS-CoV-2; stress; depression; anxiety; sleep; social support; resilience; mental health; physical health

\section{Introduction}

\section{Background}

Globally, SARS-CoV-2 has infected more than 224 million individuals, with more than 41 million cases in the United States [1]. The first report that a new coronavirus was the cause of a spate of pneumonia cases in Wuhan, China, was issued in early January 2020 by the World Health Organization, and the first case in the United States was reported two weeks later [2]. By early spring of 2020, infections had risen dramatically in several countries, and projections suggested that the pandemic could impose severe strains on the ability of US hospitals to deliver care [3]. Experience from the severe acute respiratory syndrome (SARS) outbreak in 2003 [4,5] suggested that because of its heavy burden on the health care system, the rapidly rising number of COVID-19 cases would have a large impact on the mental and physical health of the health care workforce. Such concerns indeed began to emerge early in the spring of 2020 [6]. It also seemed reasonable to expect that laboratory workers, office personnel, first responders, and others who were engaged less directly in caring for patients with COVID-19 as compared to health care workers, would experience similar strains on their psychological well-being. First responders, including police, fire, and emergency medical services, may experience higher rates of exposure to SARS-CoV-2 than the general population [7].

Health care systems in numerous countries were overwhelmed by the COVID-19 pandemic, which has caused increased pressure on frontline health workers [8]. Hospitals in New York City, for example, have had to reconfigure patient-care spaces and restructure clinical teams rapidly to address the increase in the number of patients with COVID-19 [9]. The overwhelming workload, increasing numbers of suspected and confirmed COVID-19 cases, lack of evidence-based treatments, shortages of personal protective equipment (PPE), extensive media coverage, and perceptions of inadequate support may contribute to the mental burden of health care workers [10].

Concerns of health care workers that they might not only become infected with COVID-19 but also transmit it to family members and friends add to their psychological burden [9]. The combined result is that the COVID-19 pandemic can be expected to have a prolonged impact on the mental health of a broad range of workers who are essential for delivering health care $[11,12]$.

\section{Rationale}

In the context of the COVID-19 pandemic, we anticipated that health care workers would face anxiety and depressive symptoms due to traumatic patient-care experiences and the risk of SARS-CoV-2 infection to family, friends, and colleagues [13]. Frontline health care workers were among the most vulnerable groups at risk of mental health issues during the early phases of the COVID-19 pandemic; however, the numerous risks to the well-being of health care workers remain poorly understood [14]. High prevalence of anxiety and depressive symptoms among frontline health care workers caring for patients with COVID-19 has been reported [14], but their duration and impact on future physical health are not known. The risks to the mental well-being of health care workers are likely multifaceted, with a dearth of information regarding who might benefit from preventive interventions [15].

Even under normal circumstances, workplace stress has effects on physical health [16], and these effects increase as decision latitude and control over work decrease [17]. With rapidly increasing caseloads in health care facilities, the COVID-19 pandemic seemed ideally constituted to create a high-demand, low-decision latitude environment. Added to this was the likelihood of a high proportion of adverse outcomes and mortality of patients due to the absence of effective treatments in the first months of the pandemic. Finally, PPE shortages $[9,14,18]$ increased the risk of infection for health care workers and those with whom they have a close relationship, including family, household members, and others, which has the potential to add to other sources of stress.

Emotional stress and stressful life events have been shown to contribute to the six leading causes of death in the United States-cancer, coronary artery disease, accidents (unintentional injuries), respiratory disorders, cirrhosis of the liver, and suicide - as well as to type 2 diabetes, sleep disorders, and other health conditions [19]. Workplace stress in particular has been associated with hypertension [20] and coronary heart disease [21]. High workplace demands and low decision latitude, combined with low rewards, are prospective risk factors for common mental disorders [22]. The effects of stressful working conditions on the short-term mental health of health care personnel during this pandemic have already begun to emerge $[9,18]$.

The effects of stress on long-term physical and mental health can take many years to become manifest. Military combat deployment $[23,24]$ and elevated symptoms of posttraumatic stress disorder (PTSD) in civilians have been associated with increased risk of hypertension, myocardial infarction, and stroke $[25,26]$. Longitudinal trends show that the likelihood of developing multiple physical symptoms over time is higher for those who were deployed in combat than those without combat experience [27].

Research on the effects of stress on the COVID-19 workforce $[9,18]$ is underway but is in its early stages [28], with mixed results [29]. Some studies have noted the potential importance of resilience in response to stress, including in health care workers [30], but adequate supporting data on the role of resilience in response to stress are lacking [31]. The COVID-19 pandemic experience of essential workers provides an opportunity to develop new information on the influence of sustained stress on the short- and long-term physical and mental 
health of the workforce involved in providing health care or to support health care personnel, as well as on the potential influence of aspects of resilience and its role in moderating the effects of stress.

Based on the extensive body of literature on the psychosocial influences on health, it is likely that the COVID-19 pandemic will have deleterious effects on the health of health care workers and support staff in a broad range of professions [32]. Over time, as COVID-19 treatments and management improve and infection rates decrease through public health measures and vaccination, we anticipate that sources of stress will decrease, resulting in a gradient of influence on health among health care workers who enroll in the COVID-19 Study of Healthcare and Support Personnel (CHAMPS) during later phases of the pandemic. The CHAMPS Study and Registry is designed to ascertain the time course and magnitude of these changes on the long-term mental and physical health of essential workers in the health care environment.

\section{Objectives}

The objective of the CHAMPS Study and Registry is to assess the short- and long-term physical, social, and behavioral health of personnel ("essential workers") involved in supporting or delivering care for patients with COVID-19. Included are first responders, maintenance and support staff working in clinical settings, and health care professionals of all specialties and services. At enrollment, baseline data were obtained on the study participants' working environment, lifestyle, and mental and physical health. Subsequent waves of data collection will obtain follow-up information after 6 months and then annually through 2024. The study was approved by the Villanova University Institutional Review Board (IRB) in May 2020.

The primary objectives of the CHAMPS study are to (1) determine the extent to which working in health care affects future physical and mental health; (2) evaluate trends over the time course of the evolving pandemic; (3) identify exposure variables that are associated with incident changes in health over time; and (4) identify factors that influence short- and long-term health. Specific hypotheses include the following:

1. Measures of mental health symptoms of anxiety, traumatic stress, depression, insomnia, disordered eating, resilience, burnout, and poor self-reported health will be more prevalent in essential workers than in the general population and greater in magnitude than reported in similar populations before the COVID-19 pandemic.

2. The severity of mental health symptoms will be associated with prevalence of SARS-CoV-2 infection rates in the geographic region in which the study participants work.

3. Mental health symptoms will persist longer among study participants with more severe symptoms.

4. Essential workers who report elevated symptoms of anxiety, traumatic stress, or depression will experience exacerbation of existing physical health conditions over time and higher incidence of new physical health conditions.

5. Severity and progression of mental and physical health conditions will be exacerbated by the degree of perceived exposure to adverse working environments, such as availability of personal protective equipment, extended working hours, and adequacy of staffing levels.

\section{Methods}

\section{Study Components}

CHAMPS consists of three components: (1) a cross-sectional study of respondents who consented to participate in a single assessment of health; (2) a longitudinal study of participants who consented to repeated waves of data collection; and (3) a registry comprised of participants who enrolled in the longitudinal study. The registry serves as a source of study participants who may be eligible for future ancillary observational studies as well as randomized clinical trials.

\section{Questionnaires}

To address the specific hypotheses, we selected validated instruments available for mental and physical health variables of interest. They are described in detail in the Measures section. Demographic, occupation, work environment, and geographic questions were written by professionals who work in health care.

\section{Participants and Recruitment}

Eligible participants were adult essential workers involved in health care. For the purposes of the CHAMPS study, essential workers were defined as adult (aged 18 years or older) health care personnel, support personnel, and first responders working in any health care facility or in the community. Included were those working in facilities that are involved in patient care, such as hospitals, clinics, private practices, or screening facilities; those directly involved in patient care (eg, physicians, nurses, phlebotomists, respiratory therapists, pharmacists); laboratory staff; service employees (office staff, maintenance, housekeeping, food service); individuals working in long-term care facilities; and first responders (eg, police officers, firefighters, emergency medical technicians, paramedics). Collectively, we refer to these as "essential workers." Enrollment took place over 13 months, from May 2020 through June 2021, throughout the United States.

Recruitment included advertising through local and national professional and trade organizations, news, social and professional media, alumni organizations, and word of mouth to describe the study and disseminate the internet link that provided access to the informed consent form and study questionnaires. Professional and trade organizations were identified and contacted. Website posts, e-newsletters, and social media were used to reach members of eligible occupations, with news or social media posts either by their group administrators or by the study team. The wider social media universe was reached through posts on university channels on various platforms, university-affiliated influencer posts, and a limited paid media campaign. Social media posts and outreach to organization leaders continued periodically throughout the recruitment period.

\section{Informed Consent}

An internet link provided access to the informed consent document that described the purpose of the study, time required 
to complete the questionnaire, duration of the study, and options for cross-sectional or longitudinal study participation. An affirmative consent response opened the baseline questionnaire. At the end of the initial survey, participants were asked to provide their email contact information for the longitudinal study and registry, which would be used to provide them with future questionnaires and information about studies for which they might qualify. The consent form also stated that information would be used only for medical research and shared only with other medical researchers. Participants were informed that they could end participation at any time.

\section{Registration}

CHAMPS has been registered at ClinicalTrials.gov (NCT04370821).

\section{Measures}

The baseline questionnaire consisted of questions related to the participants' demographic information, occupation, and work environment, followed by validated instruments on behavioral health, described below. Instruments were selected to balance validity and brevity. An open-ended question provided an opportunity to describe personal experiences of working during the COVID-19 pandemic and participants' interest in being interviewed. The measures and timepoints of data collection are outlined in Table 1.

Table 1. COVID-19 Study of Healthcare and Support Personnel (CHAMPS) measures and data collection timepoints. All data are self-reported.

\begin{tabular}{|c|c|c|c|c|c|c|c|c|}
\hline Measure & Instrument & Items, $\mathrm{n}$ & $\begin{array}{l}\text { T0 } \\
\text { (baseline) }\end{array}$ & $\begin{array}{l}\text { T1 } \\
\text { (6 months) }\end{array}$ & $\begin{array}{l}\mathrm{T} 2 \\
(\text { Year } 1)\end{array}$ & $\begin{array}{l}\mathrm{T} 3 \\
\text { (Year 2) }\end{array}$ & $\begin{array}{l}\text { T4 } \\
\text { (Year 3) }\end{array}$ & $\begin{array}{l}\text { T5 } \\
\text { (Year 4) }\end{array}$ \\
\hline Demographics & $\mathrm{N} / \mathrm{A}^{\mathrm{a}}$ & N/A & $\checkmark$ & & & & & \\
\hline Anxiety & GAD- $7^{\mathrm{b}}$ & 7 & $\checkmark$ & & $\checkmark$ & $\checkmark$ & $\checkmark$ & $\checkmark$ \\
\hline Depression & PHQ-2 ${ }^{\mathrm{c}}$ & 2 & $\checkmark$ & & $\checkmark$ & $\checkmark$ & $\checkmark$ & $\checkmark$ \\
\hline Social support & OSSS- $3^{\mathrm{d}}$ & 3 & $\checkmark$ & & & & & \\
\hline Sleep & ISI- $^{\mathrm{e}}$ & 7 & $\checkmark$ & & $\checkmark$ & $\checkmark$ & $\checkmark$ & $\checkmark$ \\
\hline Traumatic stress & IES-R ${ }^{f}$ & 22 & $\checkmark$ & & $\checkmark$ & $\checkmark$ & $\checkmark$ & $\checkmark$ \\
\hline Stress specific to COVID-19 & $\begin{array}{l}\text { Based on Wu et al [4] and } \\
\text { Chong et al [5] }\end{array}$ & 10 & $\checkmark$ & & & & & \\
\hline Resilience & $\mathrm{BRS}^{\mathrm{g}}$ & 6 & & $\checkmark$ & $\checkmark$ & $\checkmark$ & $\checkmark$ & $\checkmark$ \\
\hline Proactive Coping & $\begin{array}{l}\text { Proactive Coping Subscale } \\
\text { of the } \mathrm{PCI}^{\mathrm{h}}\end{array}$ & 14 & & $\checkmark$ & & & & \\
\hline Burnout & $\mathrm{OLBI}^{\mathrm{i}}$ & 16 & & $\checkmark$ & $\checkmark$ & $\checkmark$ & $\checkmark$ & $\checkmark$ \\
\hline Eating habits & LOCES $^{\mathrm{j}}$ & 7 & & $\checkmark$ & $\checkmark$ & $\checkmark$ & $\checkmark$ & $\checkmark$ \\
\hline Morphometric & Height, weight & 2 & & $\checkmark$ & & & & \\
\hline Alcohol and substance abuse & N/A & 2 & & $\checkmark$ & & & & \\
\hline Physical activity & N/A & 2 & & $\checkmark$ & & & & \\
\hline Health history checklist & N/A & 14 & & $\checkmark$ & $\checkmark$ & $\checkmark$ & $\checkmark$ & $\checkmark$ \\
\hline
\end{tabular}

${ }^{\mathrm{a} N}$ /A: not applicable.

${ }^{\mathrm{b}}$ GAD-7: Generalized Anxiety Disorder-7.

${ }^{\mathrm{c}}$ PHQ-2: Patient Health Questionnare-2.

${ }^{\mathrm{d}}$ OSSS-3: Oslo Social Support Scale-3.

e ISI-7: Insomnia Severity Index-7.

fIES-R: Impact of Events Scale - Revised.

${ }^{\mathrm{g}}$ BRS: Brief Resilience Scale.

${ }^{\mathrm{h}} \mathrm{PCI}$ : Proactive Coping Inventory.

${ }^{\mathrm{i}}$ OLBI: Oldenburg Burnout Inventory.

${ }^{\mathrm{j}}$ LOCES: Loss of Control Over Eating Scale. 


\section{Demographic Data, General Health Status, and SARS-CoV-2 Infection}

These will be ascertained by specific questions related to age, sex, occupation, self-reported general health, and infection status at the time of enrollment.

\section{Anxiety and Depression}

Anxiety symptoms will be assessed by the Generalized Anxiety Disorder-7 (GAD-7) [33], and depressive symptoms will be assessed by the Patient Health Questionnaire-2 (PQH-2) [19]. The GAD-7 was validated on 2740 adults, of whom 965 were interviewed by a mental health professional. The PHQ-2 includes the first 2 items of the PHQ-9, whose sensitivity and specificity are associated with the prevalence of depression [34]. These instruments were selected for their performance and brevity.

\section{Social Support}

The Oslo Social Support Scale-3 (OSSS-3) [35] will be used to measure social support. We sought a brief social support scale with good psychometric properties. With a Cronbach $\alpha$ of .640, the 3-item OSSS has good internal consistency and acceptable construct validity [35], especially for a short scale. It is scored easily, with normative values available for men and women between the ages of 14 and 91. In a cohort of adults 50 to 69 years of age who experienced adverse childhood events, moderate to strong perceived social support scores as measured by the OSSS-3 were associated with significantly lower odds of depressive symptoms [36].

\section{Sleep Quality}

The Insomnia Severity Index-7 (ISI-7) will be used to measure sleep quality. The ISI-7 has been validated as a useful clinical tool to quantify perceived insomnia severity for primary as well as secondary insomnia and in young and older patients [37]. It has also been validated for web-based applications, as the psychometric properties of the web-based version were found to be similar to those of the form version [38]. In a study of medical staff in China following the COVID-19 outbreak, ISI-7 scores were associated with anxiety levels and isolation and moderated by level of education [39].

\section{Stress \\ Stress has been associated with elevated risk of cardiovascular, metabolic, and musculoskeletal disorders [18]. Essential workers may experience stress from numerous sources that are not necessarily related to the pandemic. These may interact with stressors that are related to COVID-19 work life, suggesting that both general stress and stress specific to COVID-19 should be ascertained. We will measure traumatic stress with the Impact of Events Scale - Revised (IES-R) [40], which assesses the symptoms of PTSD. For stress specific to COVID-19, we adapted scales from $\mathrm{Wu}$ et al [4] and Chong et al [5] to assess the work environment and concerns specifically related to working in a high-risk environment.}

\section{Narrative Response Question}

The last question on the questionnaire provides the participants with an opportunity to describe their service experiences during the pandemic in narrative form for qualitative analysis, with no limits on the time or length of the narrative.

\section{Six-Month Follow-up}

The first follow-up occurred 6 months after enrollment and completion of the baseline questionnaire. Assessments included resilience, burnout, eating habits, and alcohol and substance use; physical activity; nutrition; height, weight, and weight discrimination items [41,42]; and a comprehensive health history checklist.

\section{Resilience}

Resilience will be measured by the Brief Resilience Scale (BRS), which is designed to assess the ability to bounce back from stress and to be brief [43]. It includes 3 positively and 3 negatively worded items, which is thought to reduce the effects of social desirability and positive response bias. This scale is unique because it assesses resilience rather than the attributes that contribute to resilience. Whether any aspects of resilience in middle life predict long-term health outcomes after major life events such as the COVID-19 pandemic remains to be determined.

\section{Proactive Coping}

Proactive coping is defined as a forward-looking strategy to address anticipated stressors or hardships, and it will be measured by the Proactive Coping Subscale of the Proactive Coping Inventory (PCI). We hypothesized that proactive coping would serve as a moderator of the consequences of stress. The Proactive Coping Subscale of the PCI consists of 14 items that combine autonomous goal setting with self-regulatory goal attainment cognitions and behavior. The scale showed high internal consistency, as seen in reliability measures of .85 and .80 in two samples during its development $[44,45]$.

\section{Burnout}

Burnout will be assessed by the Oldenburg Burnout Inventory (OLBI). Burnout is a psychological condition that follows highly demanding or stressful physical and mental work conditions that may be accompanied by inadequate resources $[15,46]$. Historically, the most commonly used instrument is the Maslach Burnout Inventory [47], which has been criticized on psychometric grounds because all items in each subscale are unidirectional [15]. We chose the OLBI because it avoids this problem by including positively and negatively framed items in the assessment of exhaustion and disengagement, which are two core features of burnout [15]. Moreover, the OLBI includes a stronger assessment of the cognitive aspect of work, which plays an important role in numerous health care functions. Data from the OLDI are also available from previous studies of health care workers [15].

\section{Eating Habits}

Increased caloric intake is a common response to mental stress [48]. We chose the brief, 7-item Loss of Control Over Eating Scale (LOCES) [49] to evaluate eating habits, as it maintains a good fit to the data analyzed by the original, 24-item LOCES [50]. The quality of the diet is as important as the caloric intake. We used a 2-question assessment of fruit and vegetable intake that has high specificity, based on correlations with biomarkers 
in the test population (plasma ascorbic acid, beta carotene and alpha tocopherol 24-hour urinary potassium excretion) [51].

\section{Morphometrics}

Self-reported height and weight were obtained. Weight discrimination history, namely whether the participant experienced any bias based on body weight, was assessed by a single question $[41,42]$.

\section{Alcohol and Substance Use}

We hypothesized that alcohol and substance use may increase in response to the stress of workplace demands, but we thought that a thorough screening would not be in the best interest of the overall study. We decided to limit our data to answers to two questions, namely, whether the participants' alcohol and substance use increased, was unchanged, or decreased since the start of the pandemic.

\section{Physical Activity}

We chose to assess physical activity with two brief questions: one on the amount of time the participants spent in moderate-to-vigorous physical activity, and one on whether their amount of physical activity had changed since the pandemic.

\section{Health History Checklist}

The relationship among stress, major life events, and other biopsychosocial factors has a long history of study in epidemiology and public health, with a sound mechanistic basis $[52,53,54]$. We hypothesized that the effects of working in the challenging circumstances of the COVID-19 pandemic would have effects on health over time. We obtained a comprehensive history of the participants' mental and physical health during the pandemic to enable prospective evaluation of incident conditions.

\section{Exposure Assessment}

We will define and quantify exposure to COVID-19 service burden by summing participants' scores on the Perception of Stress at Work scale developed by $\mathrm{Wu}$ and colleagues [4] in 2009 during the SARS pandemic, and we will add a point to that score for each of several additional stressors: (1) working more hours since the pandemic; (2) working in a different setting; (3) caring for patients with COVID-19; (4) changing one's living arrangement; (5) receiving a COVID-19 diagnosis; and (5) having a close contact (friend, family member, colleague, or any loved one) with a COVID-19 diagnosis (Table 2).

For this purpose, perceived stress was deemed to be an outcome of exposure, but it can also be included as an exposure variable in models that ascertain incidence of health conditions over time.

Table 2. Components of the algorithm-based score for exposure to COVID-19 service burden.

\begin{tabular}{ll}
\hline Component & Scoring \\
\hline Perception of Stress at Work scale & Score of 9-item scale \\
Working more hours & Yes=1 additional point \\
Working in a different setting & Yes=1 additional point \\
Caring for patients with COVID-19 & Yes=1 additional point \\
Changing one's living arrangement & Yes=1 additional point \\
$\begin{array}{l}\text { Receiving a COVID-19 diagnosis } \\
\text { Having close contact (friend/family member/colleague/any loved one) } \\
\text { with a COVID-19 diagnosis }\end{array}$ & Yes=1 additional point \\
\hline
\end{tabular}

\section{Annual Follow-up Questionnaires}

Annual follow-up questionnaires will include incidence of conditions and diseases, as well as selected instruments from the baseline and 6-month follow-up questionnaires. Additional items may be added in response to the evolving research literature on COVID-19 and that in other fields. Table 1 provides the anticipated data collection schedule.

\section{Registry and Ancillary Studies}

During enrollment participants were given the option of providing contact information for follow-up questionnaires, which also enrolls them in the CHAMPS Registry. The CHAMPS Registry enables recruitment of eligible individuals for clinical trials of interventions relevant to COVID-19 or other disorders or conditions, as well as for ancillary studies of basic behavioral research or observational studies that require new data collection. Anticipated ancillary studies include a detailed assessment of lifestyle factors, interactions with family life, and wellness interventions. Ancillary study proposals will be reviewed by the CHAMPS Steering Committee for relevance, scientific interest, and participant burden.

\section{Analysis}

\section{Data Management and Quality}

Data are collected through the web-based Qualtrics system. SPSS (IBM Corporation) and SAS (SAS Institute, Inc) will be used for data analysis. Initially, we will perform an exploratory analysis to establish patterns of missingness and distributions of the variables being measured. The registry data will be characterized with descriptive analyses, including frequency distributions, prevalence rates of COVID-19 testing and SARS-CoV-2 infection, and means and standard deviations of scores on the scales measuring work environment, general health status, anxiety, depressive symptoms, social support, traumatic 
stress, social support, sleep quality, and stress. Multiple logistic and linear regression methods will be used to assess baseline associations of health and well-being with estimates of exposure to COVID-19 infection and COVID-19-related stress at work. Models will be adjusted for sex, age, race/ethnicity, and job classification. Other preliminary explorations of associations between measured variables will be performed to aid the development of substudies from the registry. Follow-up health status questionnaires will enable analysis of associations between incident health events and baseline variables.

Narrative responses to the final question on the questionnaire will be analyzed using a deductive approach and thematic content analysis techniques. Multiple investigators will read the narratives provided by participants to perform coding of the significant statements made by participants. After multiple readings, investigators will generate data categories and clusters of statements and will develop themes.

\section{$\operatorname{Aim} 1$}

We will determine whether essential workers with higher COVID-19 service exposure burden will experience higher rates of stress, depression, anxiety, and substance use than the general population at the time they enroll in CHAMPS, and higher than in similar populations before the COVID-19 pandemic. We will compare exposure by type of service, occupation, and place of service (eg, clinical setting or community), controlling for age, self-reported sex, and race. We will conduct analyses to identify mediators, such as racial status, and moderators, such as proactive coping and resilience.

\section{Aim 2}

We will determine whether the severity of mental health symptoms will be associated with changes in the prevalence of SARS-CoV-2 infections by geographic region.

\section{Aim 3}

We will ascertain whether exposure to COVID-19 service burden will affect physical and mental health over time and how these are influenced by psychosocial variables (eg, stress, depression, anxiety, burnout). We will analyze whether longitudinal health outcomes are associated with type of service; severity and duration of mental health symptoms; and age, sex, race, and other variables. We anticipate that some analyses will depend on the adequacy of the sample sizes in various demographic subgroups.

\section{Aim 4}

We will obtain longitudinal data to determine whether mental health symptoms will persist longer among participants with more severe symptoms and whether these symptoms will be associated with higher incidence of physical health conditions.

\section{Aim 5}

We will ascertain the extent to which the thematic contents of the narrative responses to the final question of the questionnaires are correlated with measures of distress (stress, anxiety, depression, burnout) and moderated by measures of resilience. We will ascertain whether thematic content is a moderator or mediator of health outcomes and is associated with retention of participants over time.

\section{Results}

A review of the published literature on relationships between stressful life events and health led to the hypothesis that stress experienced by essential workers during the COVID-19 pandemic would affect their health status over time. In response, CHAMPS was designed to ascertain work-life experience during the first year of the pandemic, exposure to stress, and self-reported mental and physical health, as well as to determine effects of service during the pandemic on health over the subsequent 5 years. The CHAMPS longitudinal cohort serves as a registry for recruiting participants in future ancillary studies. After IRB approval, 2762 participants were enrolled between May 2020 and June 2021, with 1534 providing contact information for future studies and follow-up questionnaires.

\section{Discussion}

\section{Principal Considerations}

The longitudinal CHAMPS Study and Registry will provide important prospective data about relationships between extended health care-related service during a global pandemic and the future health of the health care-related workforce. Of special interest are first responders and service workers, who are less often included in such studies, as well as a broad ethnic diversity of participants. The lengthy enrollment period as the pandemic progresses should result in a sample with a wide range of exposures to various working conditions, thereby providing insights into the potential attributes that contribute to changes in health over time. Assessments of an extensive range of psychosocial factors, such as lifestyle habits, resilience, and pre-existing conditions, will enable assessment of their influence on mental and physical health.

The CHAMPS Registry is designed to provide opportunities for investigating additional questions and potential extension of data collection for specific hypotheses. The CHAMPS Registry anticipates ancillary studies of behavioral and biological mechanisms of action, studies of lifestyle changes and health, the effects of the pandemic on extended families, and potential randomized trials of interventions.

Altogether, CHAMPS has the potential to provide advances in knowledge about the role of chronic stress in health. The value of the study for some questions, such as identification of associations with various demographic variables, depends on the availability of a sufficient sample size of participants. We anticipate that over time, the study findings will inform public health policy relevant to national health emergencies.

\section{Limitations}

This is a convenience sample, which limits the generalizability of the results to the entire population of essential workers. Some occupation categories will have small sample sizes; thus, we may not have sufficient representation for individual analyses. Self-selection bias may also be a factor if some individuals decline to participate due to reluctance to be perceived as not 
supportive of their institutions. The measurement of COVID-19 service exposure relies on an algorithm that should be evaluated against an independent data set. Finally, the planned longitudinal analyses will depend on retaining a sufficient proportion of participants over time.

\section{Acknowledgments}

CHAMPS is supported by grants from Travere Therapeutics Inc, McKesson Corporation, anonymous donors, and internal funding from the M. Louise Fitzpatrick College of Nursing at Villanova University. We thank Anita Burry; Sharon Roth-DeFulvio, BIS, MCSE; and Robert L Sando, MGA, for their expert information technology support, and Ms Sandra Schultz for administrative management of the study. The study could not be conducted without their dedicated contribution of time and effort.

\section{Authors' Contributions}

The CHAMPS Study Investigators are as follows: coprincipal investigators: PGK, PhD; DSH, PhD, RN, FAAN; JLM, PhD, FAED; coinvestigators: PKB, PhD, RN, FAAN; HMB, PhD, RN, NP-C; LCC, PhD, RN, PMHCNS, BC, CNE, ANEF, NCC, CGP, FAPA; AC, MS; CD, MSN, RN; JDD, MSN; LM, PhD, RN; ABM, MSN, RN; SCS, EdD, RN, FAAN; and JY, PhD, RN, FAAN; data analysis core: JLM, AC, Robert L Sando, MGA, and Mu-hsun Chen, BA; lifestyle study: Tracy L Oliver, PhD; Rebecca Shenkman, MPH; and Lisa K Diewald, MS; family health study: LCC; Janette E Herbers, PhD; Michelle McKay, PhD, RN, CCRN; Amy McKeever, PhD, RN, CRNP, WHNP-BC; Helene Moriarty, PhD, RN, FAAN; Michelle M Kelly, PhD, CRNP, CNE; and Christine A Pariseault, PhD, RN (Widener University), Abigail Knight MSN student and Isabel Mahan, BSN student; biofeedback study: JLM; Guy M Weissinger II, MPhil, PhD, RN; Mary Ann Cantrell, PhD, RN, CNE, ANEF, FAAN; Rachel Baskin, MSN, RN, CPN; Cerena George, MSN; Alexis Cohn, BSN student and Rachel Randall, BSN student.

\section{Conflicts of Interest}

None declared.

\section{References}

1. COVID-19 data repository. Johns Hopkins Coronavirus Resource Center. URL: https://coronavirus.jhu.edu/ [accessed 2021-05-04]

2. Holshue ML, DeBolt C, Lindquist S, Lofy KH, Wiesman J, Bruce H, et al. First case of 2019 novel coronavirus in the United States. N Engl J Med 2020 Mar 05;382(10):929-936. [doi: 10.1056/nejmoa2001191]

3. Khera R, Jain S, Lin Z, Ross J, Krumholz H. Evaluation of the anticipated burden of COVID-19 on hospital-based healthcare services across the United States. medRxiv. Preprint posted online on April 03, 2020 [FREE Full text] [doi: 10.1101/2020.04.01.20050492] [Medline: 32511584]

4. Wu P, Fang Y, Guan Z, Fan B, Kong J, Yao Z, et al. The psychological impact of the SARS epidemic on hospital employees in China: exposure, risk perception, and altruistic acceptance of risk. Can J Psychiatry 2009 May 01;54(5):302-311 [FREE Full text] [doi: $10.1177 / 070674370905400504]$ [Medline: 19497162 ]

5. Chong M, Wang W, Hsieh W, Lee C, Chiu N, Yeh W, et al. Psychological impact of severe acute respiratory syndrome on health workers in a tertiary hospital. Br J Psychiatry 2004 Aug 02;185(2):127-133. [doi: 10.1192/bjp.185.2.127] [Medline: 15286063]

6. Maben J, Bridges J. Covid-19: Supporting nurses' psychological and mental health. J Clin Nurs 2020 Aug 02;29(15-16):2742-2750 [FREE Full text] [doi: 10.1111/jocn.15307] [Medline: 32320509]

7. Niu J, Rodriguez J, Sareli C, Goldman J, Puga M, Eckardt P. COVID-19 infection among first responders in Broward County, Florida, March-April 2020. J Public Health (Oxf) 2021 Sep 22;43(3):450-454 [FREE Full text] [doi: 10.1093/pubmed/fdaa231] [Medline: 33367792]

8. Deng D, Naslund J. Psychological impact of COVID-19 pandemic on frontline health workers in low- and middle-income countries. Harv Public Health Rev (Camb) 2020;28 [FREE Full text] [Medline: 33409499]

9. Shechter A, Diaz F, Moise N, Anstey DE, Ye S, Agarwal S, et al. Psychological distress, coping behaviors, and preferences for support among New York healthcare workers during the COVID-19 pandemic. Gen Hosp Psychiatry 2020 Sep;66:1-8 [FREE Full text] [doi: 10.1016/j.genhosppsych.2020.06.007] [Medline: 32590254]

10. Lai J, Ma S, Wang Y, Cai Z, Hu J, Wei N, et al. Factors associated with mental health outcomes among health care workers exposed to coronavirus disease 2019. JAMA Netw Open 2020 Mar 02;3(3):e203976 [FREE Full text] [doi: 10.1001/jamanetworkopen.2020.3976] [Medline: $\underline{\text { 32202646] }}$

11. Blake H, Bermingham F, Johnson G, Tabner A. Mitigating the psychological impact of COVID-19 on healthcare workers: a digital learning package. Int J Environ Res Public Health 2020 Apr 26;17(9):2997 [FREE Full text] [doi: 10.3390/ijerph17092997] [Medline: 32357424]

12. Pollock AM, Lancaster J. Asymptomatic transmission of covid-19. BMJ 2020 Dec 21:m4851. [doi: 10.1136/bmj.m4851]

13. Heath C, Sommerfield A, von Ungern-Sternberg BS. Resilience strategies to manage psychological distress among healthcare workers during the COVID-19 pandemic: a narrative review. Anaesthesia 2020 Oct;75(10):1364-1371 [FREE Full text] [doi: 10.1111/anae.15180] [Medline: $\underline{32534465]}$ 
14. Salari N, Khazaie H, Hosseinian-Far A, Khaledi-Paveh B, Kazeminia M, Mohammadi M, et al. The prevalence of stress, anxiety and depression within front-line healthcare workers caring for COVID-19 patients: a systematic review and meta-regression. Hum Resour Health 2020 Dec 17;18(1):100 [FREE Full text] [doi: 10.1186/s12960-020-00544-1] [Medline: 33334335]

15. Demerouti E, Bakker AB, Nachreiner F, Schaufeli WB. A model of burnout and life satisfaction amongst nurses. J Adv Nurs 2000 Aug;32(2):454-464. [doi: 10.1046/j.1365-2648.2000.01496.x] [Medline: 10964195]

16. Steptoe A, Kivimäki M. Stress and cardiovascular disease. Nat Rev Cardiol 2012 Apr 03;9(6):360-370. [doi: 10.1038/nrcardio.2012.45] [Medline: 22473079]

17. Stahl SM, Hauger RL. Stress: an overview of the literature with emphasis on job-related strain and intervention. Adv Ther 1994;11(3):110-119. [Medline: 10150261]

18. Vizheh M, Qorbani M, Arzaghi SM, Muhidin S, Javanmard Z, Esmaeili M. The mental health of healthcare workers in the COVID-19 pandemic: a systematic review. J Diabetes Metab Disord 2020 Oct 26:1-12 [FREE Full text] [doi: 10.1007/s40200-020-00643-9] [Medline: 33134211]

19. Salleh MR. Life event, stress and illness. Malays J Med Sci 2008 Oct;15(4):9-18 [FREE Full text] [Medline: 22589633]

20. Landsbergis PA, Dobson M, Koutsouras G, Schnall P. Job strain and ambulatory blood pressure: a meta-analysis and systematic review. Am J Public Health 2013 Mar;103(3):e61-e71. [doi: 10.2105/ajph.2012.301153]

21. Kivimäki M, Nyberg ST, Fransson EI, Heikkilä K, Alfredsson L, Casini A, IPD-Work Consortium. Associations of job strain and lifestyle risk factors with risk of coronary artery disease: a meta-analysis of individual participant data. CMAJ 2013 Jun 11;185(9):763-769 [FREE Full text] [doi: 10.1503/cmaj.121735] [Medline: 23670152]

22. Stansfeld S, Candy B. Psychosocial work environment and mental health--a meta-analytic review. Scand J Work Environ Health 2006 Dec;32(6):443-462 [FREE Full text] [doi: 10.5271/sjweh.1050] [Medline: 17173201]

23. Granado NS, Smith TC, Swanson GM, Harris RB, Shahar E, Smith B, Millennium Cohort Study Team. Newly reported hypertension after military combat deployment in a large population-based study. Hypertension 2009 Nov;54(5):966-973. [doi: 10.1161/HYPERTENSIONAHA.109.132555] [Medline: 19752293]

24. Porter B, Bonanno GA, Bliese PD, Phillips CJ, Proctor SP, Millennium Cohort Study. Combat and trajectories of physical health functioning in U.S. service members. Am J Prev Med 2019 Nov;57(5):637-644 [FREE Full text] [doi: 10.1016/j.amepre.2019.06.015] [Medline: 31564607]

25. Sumner JA, Kubzansky LD, Elkind MSV, Roberts AL, Agnew-Blais J, Chen Q, et al. Trauma exposure and posttraumatic stress disorder symptoms predict onset of cardiovascular events in women. Circulation 2015 Jul 28;132(4):251-259 [FREE Full text] [doi: 10.1161/CIRCULATIONAHA.114.014492] [Medline: 26124186]

26. Sumner JA, Kubzansky LD, Roberts AL, Gilsanz P, Chen Q, Winning A, et al. Post-traumatic stress disorder symptoms and risk of hypertension over 22 years in a large cohort of younger and middle-aged women. Psychol Med 2016 Aug 18;46(15):3105-3116. [doi: 10.1017/s0033291716001914]

27. McCutchan PK, Liu X, LeardMann CA, Smith TC, Boyko EJ, Gore KL, et al. Deployment, combat, and risk of multiple physical symptoms in the US military: a prospective cohort study. Ann Epidemiol 2016 Mar;26(2):122-128. [doi: 10.1016/j.annepidem.2015.12.001] [Medline: 26781443]

28. Allan SM, Bealey R, Birch J, Cushing T, Parke S, Sergi G, et al. The prevalence of common and stress-related mental health disorders in healthcare workers based in pandemic-affected hospitals: a rapid systematic review and meta-analysis. Eur J Psychotraumatol 2020 Oct 16;11(1):1810903 [FREE Full text] [doi: 10.1080/20008198.2020.1810903] [Medline: 33244359]

29. Milgrom Y, Tal Y, Finestone AS. Comparison of hospital worker anxiety in COVID-19 treating and non-treating hospitals in the same city during the COVID-19 pandemic. Isr J Health Policy Res 2020 Oct 21;9(1):55 [FREE Full text] [doi: 10.1186/s13584-020-00413-1] [Medline: 33087169]

30. Lorente L, Vera M, Peiró T. Nurses' stressors and psychological distress during the COVID-19 pandemic: the mediating role of coping and resilience. J Adv Nurs 2021 Mar 04;77(3):1335-1344 [FREE Full text] [doi: 10.1111/jan.14695] [Medline: 33210768]

31. Glonti K, Gordeev VS, Goryakin Y, Reeves A, Stuckler D, McKee M, et al. A systematic review on health resilience to economic crises. PLoS One 2015 Apr 23;10(4):e0123117 [FREE Full text] [doi: 10.1371/journal.pone.0123117] [Medline: 25905629]

32. Saladino V, Algeri D, Auriemma V. The psychological and social impact of COVID-19: New perspectives of well-being. Front Psychol 2020 Oct 2;11:577684 [FREE Full text] [doi: 10.3389/fpsyg.2020.577684] [Medline: 33132986]

33. Spitzer RL, Kroenke K, Williams JBW, Löwe B. A brief measure for assessing generalized anxiety disorder: the GAD-7. Arch Intern Med 2006 May 22;166(10):1092-1097. [doi: 10.1001/archinte.166.10.1092] [Medline: 16717171]

34. Kroenke K, Spitzer RL, Williams JBW. The Patient Health Questionnaire-2: validity of a two-item depression screener. Med Care 2003 Nov;41(11):1284-1292. [doi: 10.1097/01.MLR.0000093487.78664.3C] [Medline: 14583691]

35. Kocalevent R, Berg L, Beutel ME, Hinz A, Zenger M, Härter M, et al. Social support in the general population: standardization of the Oslo social support scale (OSSS-3). BMC Psychol 2018 Jul 17;6(1):31 [FREE Full text] [doi:

10.1186/s40359-018-0249-9] [Medline: 30016997] 
36. Cheong E, Sinnott C, Dahly D, Kearney P. Adverse childhood experiences (ACEs) and later-life depression: perceived social support as a potential protective factor. BMJ Open 2017 Sep 01;7(9):e013228 [FREE Full text] [doi: 10.1136/bmjopen-2016-013228] [Medline: 28864684]

37. Bastien C, Vallières A, Morin CM. Validation of the Insomnia Severity Index as an outcome measure for insomnia research. Sleep Med 2001 Jul;2(4):307. [doi: 10.1016/s1389-9457(00)00065-4]

38. Thorndike FP, Ritterband LM, Saylor DK, Magee JC, Gonder-Frederick LA, Morin CM. Validation of the insomnia severity index as a web-based measure. Behav Sleep Med 2011 Sep 30;9(4):216-223. [doi: 10.1080/15402002.2011.606766] [Medline: 22003975]

39. Zhang C, Yang L, Liu S, Ma S, Wang Y, Cai Z, et al. Survey of insomnia and related social psychological factors among medical staff involved in the 2019 novel coronavirus disease outbreak. Front Psychiatry 2020;11:306 [FREE Full text] [doi: 10.3389/fpsyt.2020.00306] [Medline: 32346373]

40. Printz C. Psychological stress is associated with a higher risk of cervical cancer mortality. Cancer 2020 Jan 15;126(2):240-241 [FREE Full text] [doi: 10.1002/cncr.32686] [Medline: 31917471]

41. Kyle TK, Puhl RM. Putting people first in obesity. Obesity (Silver Spring) 2014 May;22(5):1211 [FREE Full text] [doi: 10.1002/oby.20727] [Medline: 24616446]

42. Phelan SM, Dovidio JF, Puhl RM, Burgess DJ, Nelson DB, Yeazel MW, et al. Implicit and explicit weight bias in a national sample of 4,732 medical students: the medical student CHANGES study. Obesity (Silver Spring) 2014 Apr;22(4):1201-1208 [FREE Full text] [doi: 10.1002/oby.20687] [Medline: 24375989]

43. Smith BW, Dalen J, Wiggins K, Tooley E, Christopher P, Bernard J. The brief resilience scale: assessing the ability to bounce back. Int J Behav Med 2008;15(3):194-200. [doi: 10.1080/10705500802222972] [Medline: 18696313]

44. Greenglass E, Schwarzer R, Jakubiec D, Fiksenbaum L, Taubert S. The Proactive Coping Inventory (PCI): A multidimensional research instrument. 1999 Presented at: 20th International Conference of the Stress and Anxiety Research Society (STAR); July 12-14, 1999; Cracow, Poland URL: https://estherg.info.yorku.ca/files/2014/09/pci.pdf

45. Greenglass ER, Fiksenbaum L. Proactive coping, positive affect, and well-being. Eur Psychol 2009 Jan;14(1):29-39. [doi: 10.1027/1016-9040.14.1.29]

46. Maslach C, Schaufeli WB, Leiter MP. Job burnout. Annu Rev Psychol 2001;52:397-422. [doi: 10.1146/annurev.psych.52.1.397] [Medline: 11148311]

47. Maslach C, Jackson SE. The measurement of experienced burnout. J Organiz Behav 1981 Apr;2(2):99-113. [doi: 10.1002/job.4030020205]

48. Dallman MF, Pecoraro N, Akana SF, La Fleur SE, Gomez F, Houshyar H, et al. Chronic stress and obesity: a new view of "comfort food". Proc Natl Acad Sci U S A 2003 Sep 30;100(20):11696-11701 [FREE Full text] [doi: 10.1073/pnas.1934666100] [Medline: 12975524]

49. Bodell LP, Forney KJ, Chavarria J, Keel PK, Wildes JE. Self-report measures of loss of control over eating: psychometric properties in clinical and non-clinical samples. Int J Eat Disord 2018 Nov 28;51(11):1252-1260. [doi: 10.1002/eat.22957] [Medline: $\underline{30265751]}$

50. Latner JD, Mond JM, Kelly MC, Haynes SN, Hay PJ. The Loss of Control Over Eating Scale: development and psychometric evaluation. Int J Eat Disord 2014 Sep 26;47(6):647-659. [doi: 10.1002/eat.22296] [Medline: 24862351]

51. Cappuccio FP, Rink E, Perkins-Porras L, McKay C, Hilton S, Steptoe A. Estimation of fruit and vegetable intake using a two-item dietary questionnaire: a potential tool for primary health care workers. Nutr Metab Cardiovasc Dis 2003 Mar;13(1):12-19. [doi: 10.1016/s0939-4753(03)80163-1] [Medline: 12772433]

52. McEwen B. Stress, adaptation, and disease: allostasis and allostatic load. Ann N Y Acad Sci 1998 May 01;840(1):33-44. [doi: 10.1111/j.1749-6632.1998.tb09546.x] [Medline: 9629234$]$

53. McEwen BS. Brain on stress: how the social environment gets under the skin. Proc Natl Acad Sci U S A 2012 Oct 16;109 Suppl 2(Supplement_2):17180-17185 [FREE Full text] [doi: 10.1073/pnas.1121254109] [Medline: 23045648]

54. Kaufmann PG, McMahon RP, Becker LC, Bertolet B, Bonsall R, Chaitman B, et al. he psychophysiological investigations of myocardial ischemia (PIMI) study: Objective, methods, and variability of measures. Psychosom Med 1998;60(1):56-63. [doi: 10.1097/00006842-199801000-00014] [Medline: 9492241]

\section{Abbreviations}

BRS: Brief Resilience Scale

CHAMPS: COVID-19 Study of Healthcare and Support Personnel

GAD-7: Generalized Anxiety Disorder-7

IES-R: Impact of Events Scale - Revised

IRB: Institutional Review Board

ISI-7: Insomnia Severity Index-7

LOCES: Loss of Control Over Eating Scale

OLBI: Oldenburg Burnout Inventory

OSSS-3: Oslo Social Support Scale-3 
PCI: Proactive Coping Inventory

PHQ-2: Patient Health Questionnaire-2

PTSD: posttraumatic stress disorder

SARS: severe acute respiratory syndrome

Edited by G Eysenbach; submitted 14.06.21; peer-reviewed by S Newman; comments to author 06.07.21; revised version received 26.09.21; accepted 26.09.21; published 07.10.21

Please cite as:

Kaufmann PG, Havens DS, Mensinger JL, Bradley PK, Brom HM, Copel LC, Costello A, D'Annunzio C, Dean Durning J, Maldonado L, Barrow McKenzie A, Smeltzer SC, Yost J, CHAMPS Study Investigators

The COVID-19 Study of Healthcare and Support Personnel (CHAMPS): Protocol for a Longitudinal Observational Study

JMIR Res Protoc 2021;10(10):e30757

URL: https://www.researchprotocols.org/2021/10/e30757

doi: $10.2196 / 30757$

PMID: $\underline{34582354}$

CPeter G Kaufmann, Donna S Havens, Janell L Mensinger, Patricia K Bradley, Heather M Brom, Linda C Copel, Alexander Costello, Christine D'Annunzio, Jennifer Dean Durning, Linda Maldonado, Ann Barrow McKenzie, Suzanne C Smeltzer, Jennifer Yost, CHAMPS Study Investigators. Originally published in JMIR Research Protocols (https://www.researchprotocols.org), 07.10.2021. This is an open-access article distributed under the terms of the Creative Commons Attribution License (https://creativecommons.org/licenses/by/4.0/), which permits unrestricted use, distribution, and reproduction in any medium, provided the original work, first published in JMIR Research Protocols, is properly cited. The complete bibliographic information, a link to the original publication on https://www.researchprotocols.org, as well as this copyright and license information must be included. 